\section{6 OPEN ACCESS}

\title{
Therapeutic effects of $0.1 \%$ tacrolimus eye drops for refractory allergic ocular diseases with proliferative lesion or corneal involvement
}

\author{
Atsuki Fukushima, ${ }_{1}^{1}$ Yuichi Ohashi, ${ }^{2}$ Nobuyuki Ebihara, ${ }^{3}$ Eiichi Uchio, ${ }^{4}$ \\ Shigeki Okamoto, ${ }^{5}$ Naoki Kumagai, ${ }^{6}$ Jun Shoji, ${ }^{7}$ Etsuko Takamura, ${ }^{8}$ Yayoi Nakagawa, ${ }^{9}$ \\ Kenichi Namba, ${ }^{10}$ Hiroshi Fujishima, ${ }^{11}$ Dai Miyazaki ${ }^{12}$
}

For numbered affiliations see end of article.

\section{Correspondence to} Dr Atsuki Fukushima, Department of Ophthalmology, Kochi Medical School, Oko-cho Kohasu, Nankoku-shi, Kochi 783-8505, Japan; fukusima@kochi-u.ac.jp

Received 9 October 2013 Revised 26 December 2013 Accepted 16 March 2014 Published Online First 2 April 2014

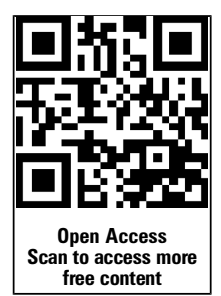

\section{ABSTRACT}

Background The objective of this study was to investigate the efficacy of topical $0.1 \%$ tacrolimus in treating refractory allergic conjunctivitis with proliferative lesions and/or corneal involvement.

Methods This prospective observational study included 1436 patients with refractory allergic conjunctivitis whose condition had responded poorly to conventional antiallergic drugs and/or topical steroids and/or topical cyclosporine. All patients received tacrolimus eye drops twice daily during the study period. Ten clinical signs and six clinical symptoms were rated on a four-grade scale. The primary endpoint was the change from baseline in total clinical signs and symptoms score at the last observation or following 6 months of treatment. Results Total signs and symptoms score significantly decreased after 1 month of treatment $(p<0.001)$. Giant papillae and corneal lesions were also reduced by tacrolimus eye drop use $(p<0.001)$. The drug proved effective in patients whose condition did not respond well to topical cyclosporine therapy. About $50 \%$ of all patients using topical steroids were weaned. The most common adverse reaction was a transient burning sensation (3.20\%).

Conclusions Tacrolimus eye drops are highly effective in treating refractory allergic conjunctivitis with proliferative lesions and/or corneal involvement, and may reduce or replace topical steroid use.

Trial registration number UMIN 000008640.

\section{INTRODUCTION}

Severe allergic conjunctival diseases (ACDs), such as atopic keratoconjunctivitis (AKC) and vernal keratoconjunctivitis (VKC), are occasionally complicated by keratopathy. ${ }^{1}$ Severe keratopathy, such as a shield ulcer, is a serious pathological condition because it may result in reduced visual acuity. ${ }^{2}$ Keratopathy associated with severe ACD is primarily caused by the histotoxic protein produced by eosinophils $^{3}$ and eosinophils massively infiltrate giant papillae tissue in patients with severe ACD. Therefore, alleviation of giant papillae with surgical resection is a widely used treatment in the cases that do not respond to medical treatment. Drug therapy for severe ACD often utilises topical and oral antiallergic agents or steroids. However, antiallergic agents often have insufficient efficacy and long-term patient management is usually required with this therapy. ${ }^{4}$ The use of ocular steroids is associated with a serious increased risk of ocular hypertension, cataracts and/or glaucoma. $^{2} 5$ Additionally, the risk of steroid-induced ocular hypertension is particularly high in children less than 10 years old and a cataract-induced visual acuity reduction during infancy or early childhood markedly affects a patient's quality of life. ${ }^{6}$

Tacrolimus is a 23-member cyclic macrolide lactone and was isolated from Streptomyces tsukubaensis in $1984 .^{7}$ It was initially developed as an immunosuppressant agent for use following organ transplantation, but is now clinically available worldwide. Tacrolimus ointment is also marketed for the treatment of atopic dermatitis.

Tacrolimus binds to FK506-binding proteins within $\mathrm{T}$ lymphocytes and inhibits calcineurin activity. Calcineurin inhibition suppresses dephosphorylation of the nuclear factor of activated T cells and its transfer into the nucleus, which results in suppressed formation of $\mathrm{T}$ helper 1 (Th1) (interleukin (IL)-2, interferon $\gamma$ ) and Th2 cytokines (IL-4, IL-5). ${ }^{8}$ Tacrolimus has also been reported to inhibit histamine release from mast cells and is thought to alleviate allergic symptoms through these mechanisms. ${ }^{9}$

Previously, tacrolimus was administered as an in-house formulation in a solute of castor oil, olive oil or dextrin. ${ }^{10-12}$ The ointment form of tacrolimus was also useful in treating refractory inflammatory disease of the outer ocular area. Unfortunately, these formulations are known to cause irritation and epithelial keratitis, so information on their efficacy is sporadic and limited. ${ }^{13}$ Herein, we evaluate the efficacy of tacrolimus eye drops in treating refractory allergic ocular disease in 1436 patients treated with topical tacrolimus. We show that topical tacrolimus is highly effective in treating $\mathrm{AKC}$ and $\mathrm{VKC}$, and may reduce or replace steroid therapy for these conditions.

\section{METHODS}

\section{Eligibility criteria and diagnosis}

All patients included in this study were treated with tacrolimus eye drops and the study was designed as follows. Tacrolimus ophthalmic suspension, $0.1 \%$ (Senju Pharmaceutical Co., Osaka, Japan) was used in eyes with severe allergic conjunctivitis that responded poorly to conventional antiallergic agents such as antiallergic ophthalmic solutions, topical steroids and/or cyclosporine. All patients registered and treated with tacrolimus eye drops between May 2008 and August 2010 were included in the study. Patients with a known sensitivity to 
tacrolimus hydrate or any tacrolimus eye drop component, an infectious eye disease, or a confirmed or possible pregnancy were excluded.

The protocol for this study was reviewed by the Ethics Committee of the Pharmaceuticals and Medical Devices Agency in Japan. The clinical trial registration ID is UMIN 000008640. A diagnosis was made according to published guidelines for allergic conjunctival diseases. ${ }^{3} 1415$ Patients satisfying the following requirements were included in analyses: presence of conjunctival giant papillae, limbal swelling, and/or Trantas dots ${ }^{14}$; persistent or relapsing conjunctivitis $\operatorname{sign}^{14}$; and younger than 40 years of age. ${ }^{31416}$

One drop of tacrolimus was administered twice a day to patients with refractory allergic ocular diseases with proliferative lesions and/or corneal involvement. The maximum observation period was 6 months. Each of 10 clinical signs (table 1) was scored on a four-point scale using the following definitions: $0=$ none, $1=$ mild, $2=$ moderate and $3=$ severe. $^{316}$ Grades were

Table 1 Grading scales for clinical signs

\begin{tabular}{|c|c|c|}
\hline Signs & Score & Definition \\
\hline \multirow[t]{4}{*}{$\begin{array}{l}\text { Palpebral conjunctiva } \\
\text { Hyperaemia }\end{array}$} & 3 & $\begin{array}{l}\text { Impossible to distinguish individual blood } \\
\text { vessels }\end{array}$ \\
\hline & 2 & Dilatation of many vessels \\
\hline & 1 & Dilatation of several vessels \\
\hline & 0 & None \\
\hline \multirow[t]{4}{*}{ Oedema } & 3 & Diffuse oedema with opacity \\
\hline & 2 & Thinner diffuse oedema \\
\hline & 1 & Slight oedema \\
\hline & 0 & None \\
\hline \multirow[t]{4}{*}{ Follicles } & 3 & 20 or more follicles \\
\hline & 2 & 10-19 follicles \\
\hline & 1 & 1-9 follicles \\
\hline & 0 & None \\
\hline \multirow[t]{4}{*}{ Papillae } & 3 & Papillae size: $0.6 \mathrm{~mm}$ or more \\
\hline & 2 & Papillae size: $0.3-0.5 \mathrm{~mm}$ \\
\hline & 1 & Papillae size: $0.1-0.2 \mathrm{~mm}$ \\
\hline & 0 & None \\
\hline \multirow[t]{4}{*}{$\begin{array}{l}\text { Giant papillae (papillae } \\
\text { size } \geq 1 \mathrm{~mm} \text { ) }\end{array}$} & 3 & $\begin{array}{l}\text { Elevated papillae in } 1 / 2 \text { or more of the } \\
\text { upper palpebral conjunctiva }\end{array}$ \\
\hline & 2 & $\begin{array}{l}\text { Elevated papillae in }<1 / 2 \text { of the upper } \\
\text { palpebral conjunctiva }\end{array}$ \\
\hline & 1 & Flat papillae \\
\hline & 0 & None \\
\hline \multirow[t]{4}{*}{$\begin{array}{l}\text { Bulbar conjunctiva } \\
\text { Hyperaemia }\end{array}$} & 3 & $\begin{array}{l}\text { Diffuse dilated blood vessels over the entire } \\
\text { bulbar conjunctiva }\end{array}$ \\
\hline & 2 & Dilatation of many vessels \\
\hline & 1 & Dilatation of several vessels \\
\hline & 0 & None \\
\hline \multirow[t]{4}{*}{ Oedema } & 3 & Bullous oedema \\
\hline & 2 & Thinner diffuse oedema \\
\hline & 1 & Localised oedema \\
\hline & 0 & None \\
\hline Limbus & 3 & 9 or more dots \\
\hline \multirow[t]{3}{*}{ Trantas' dot } & 2 & $5-8$ dots \\
\hline & 1 & $1-4$ dots \\
\hline & 0 & None \\
\hline \multirow[t]{4}{*}{ Swelling } & 3 & $\begin{array}{l}\text { Found in } 2 / 3 \text { or more of the limbal } \\
\text { circumference }\end{array}$ \\
\hline & 2 & $\begin{array}{l}\text { Found in } 1 / 3 \text { to }<2 / 3 \text { of the limbal } \\
\text { circumference }\end{array}$ \\
\hline & 1 & Found in $<1 / 3$ of the limbal circumference \\
\hline & 0 & None \\
\hline \multirow[t]{4}{*}{ Corneal epithelial signs } & 3 & Shield ulcer or corneal erosion \\
\hline & 2 & Exfoliation superficial punctate keratitis \\
\hline & 1 & Superficial punctate keratitis \\
\hline & 0 & None \\
\hline
\end{tabular}

assigned based on photographic criteria (table 1, photographic images not shown). ${ }^{3}$ In addition, each of six symptoms, including itching, discharge, lacrimation, photophobia, foreign body sensation and eye pain, was scored on a four-grade scale. Scoring was done at baseline (therapy initiation) and at 1, 2, 3 and 6 months into tacrolimus eye drop therapy. In cases when tacrolimus therapy was discontinued, observations made on the last day of administration were used as the last observation.

Demographic variables collected and examined included gender, age, allergic disease complications, previously used drugs, concomitant drugs and adverse reactions. The primary efficacy endpoint was the change in total signs and symptom scores from baseline.

\section{Statistical analyses}

Data are presented as mean $\pm S D$. Statistical analyses were performed using JMP statistical software (V.9 for Windows, SAS Institute Inc, Cary, North Carolina, USA). Statistical significance was defined as a two-sided $p$ value of $<0.05$. Efficacy assessments were based on measurements obtained from the eye with a higher total ocular findings score (worse disease) ${ }^{17}$ and the Wilcoxon signed rank test was used to compare total scores before and after treatment.

\section{RESULTS}

\section{Patient profile}

Table 2 summarises the demographic variables of the 1436 patients included in analyses. The percentage of male patients was $77.6 \%$. Mean patient age was $15.8 \pm 8.9$ years at the time of enrolment and $8.3 \pm 4.2$ years at the time of disease onset. Allergic rhinitis and asthma were also present in $23.5 \%$ and $17.6 \%$ of patients, respectively. Of all patients analysed, $54.6 \%$ had previously used antiallergic ophthalmic solutions such as antihistamine and mast cell stabiliser, $53.3 \%$ had previously used steroid ophthalmic solutions, and $35.3 \%$ had previously used cyclosporine eye drop $0.1 \%$.

\section{Change in signs and symptoms with topical tacrolimus eye drop use}

The total score of the 10 clinical signs (range 0-30) and 6 clinical symptoms (range 0-18) significantly decreased from baseline 1 month after beginning tacrolimus eye drop treatment $(\mathrm{p}<0.001$, Wilcoxon signed rank test, figure 1$)$. The mean total score of clinical signs was $15.3 \pm 5.0$ at the start of treatment and decreased to $5.9 \pm 4.6$ at the last observation (mean change from baseline $=-9.4$ ). The total clinical symptom score

Table 2 Baseline characteristics of the patients

\begin{tabular}{ll}
\hline Sex & \\
Male (\%) & $1115(77.6)$ \\
Female & 321 \\
Mean age (years) \pm SD & $15.8 \pm 8.9$ \\
Mean age of onset (years) \pm SD & $8.3 \pm 4.2$ \\
Allergic complications (\%) & \\
Allergic rhinitis & $337(23.5)$ \\
Asthma & $253(17.6)$ \\
Pretreatment (\%) & $784(54.6)$ \\
Antiallergic eye drop & $765(53.3)$ \\
Topical steroids & $507(35.3)$ \\
Topical cyclosporine & \\
\hline
\end{tabular}




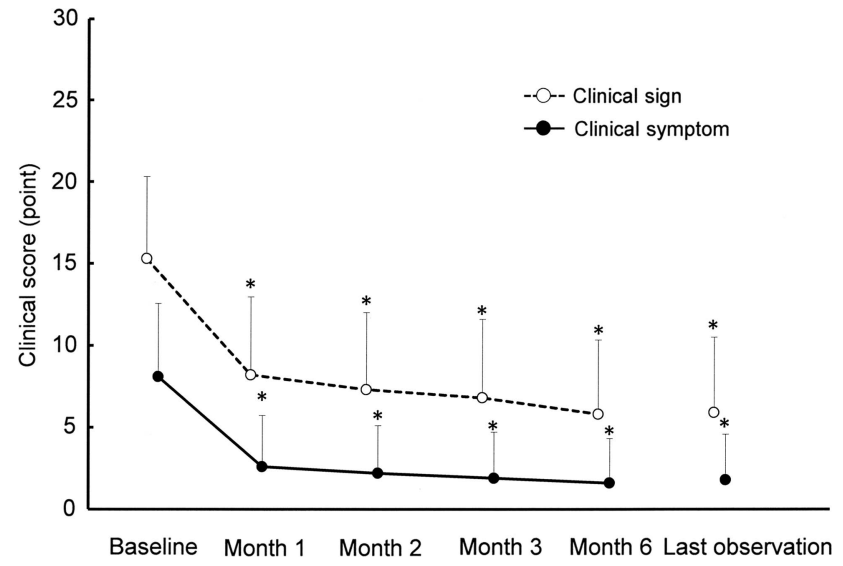

Figure 1 Change from baseline in total symptom and sign scores during the 6 -month study period ( $n=1436$ patients). Error bars represent 1 SD. The statistical significance of each score change was evaluated using the Wilcoxon signed rank test.

decreased from $8.1 \pm 4.5$ at baseline to $1.8 \pm 2.8$ at the last observation (mean change from baseline $=-6.3$ ).

\section{Giant papillae and corneal involvement score before and after tacrolimus therapy}

As shown in figure 2, 87.2\% of patients had giant papillae at baseline, with $62.8 \%$ of patients having active-stage giant papillae (score $\geq 2$ ). At the time of the last observation, only $15.8 \%$ of the patients had active-stage giant papillae, with alleviation of giant papillae (score $\leq 1)$ seen in $84.2 \%$ of patients $(\mathrm{p}<0.001$, Wilcoxon signed rank test). Superficial punctate keratopathy (SPK) was also seen in $67.8 \%$ of patients at baseline (figure 2). At the time of the last observation, the corneal epithelial disorder score was significantly lower than at baseline $(\mathrm{p}<0.001$, Wilcoxon signed rank test), with SPK prevalence lowered to $22.3 \%$. In addition, the percentage of patients with a score $\geq 2$ (large impact on visual acuity) decreased from $41.3 \%$ at baseline to $6.7 \%$ at the final evaluation.

\section{Score changes in patients unresponsive to topical cyclosporine $0.1 \%$}

Before tacrolimus eye drop therapy, 239 patients had been treated with cyclosporine eye drop $0.1 \%$ for at least 1 month, but still had giant papillae scores greater than 2 or corneal epithelial disorder scores greater than 2 at the time of tacrolimus therapy initiation. In these patients, the total clinical signs and clinical symptoms scores at the time of switching were 16.8 \pm 4.7 and $9.1 \pm 4.4$, respectively (figure 3 ). One month into tacrolimus eye drop therapy, both scores had significantly

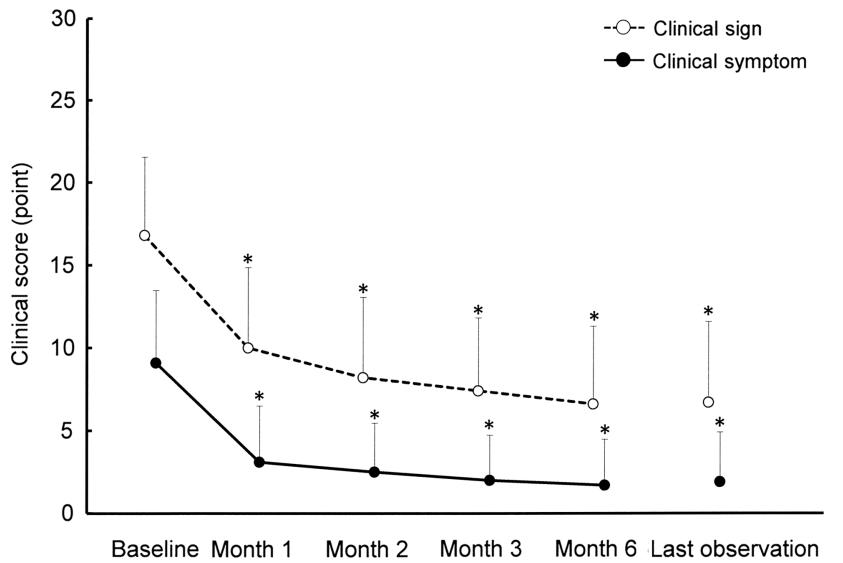

Figure 3 Changes from baseline in total sign and symptom scores in patients who did not respond well to prior cyclosporine ophthalmic solution therapy. Error bars represent 1 SD. The statistical significance of each score change was evaluated using the Wilcoxon signed rank test.

decreased ( $\mathrm{p}<0.001$, Wilcoxon signed rank test) to clinical signs score of $6.7 \pm 4.9$ (change $=-10.1$ ) and clinical symptoms score of $1.9 \pm 3.0$ (change $=-7.2$ ) at the time of the last observation.

\section{Proportion of patients on steroid therapy}

Next, we assessed the possible steroid-sparing effect of tacrolimus eye drops. The percentage of patients $(n=328$ patients at baseline) using each type of steroid ophthalmic solution progressively decreased during the tacrolimus eye drop administration period. As shown in figure $4,53.4 \%$ of patients were successfully weaned off topical steroids 6 months into tacrolimus treatment. The percentage of patients using betamethasone ophthalmic solution was $44.8 \%$ at baseline, which decreased to $16.5 \% 6$ months into tacrolimus treatment.

\section{Adverse reactions}

Adverse reactions were noted in 117 (8.15\%) of 1436 patients analysed (table 3 ). The only major adverse reaction was a transient burning sensation upon drop instillation (46 cases, 3.20\%). Corneal infections, including bacterial keratitis (two cases, $0.14 \%$ ), herpetic keratitis (two cases, $0.14 \%$ ) and a bacterial corneal ulcer (one case, $0.07 \%$ ) were also observed. In these five patients, atopic dermatitis or asthma was also noted as an underlying condition. In addition, intraocular pressure elevation occurred in three patients, presumably from adjunctive topical steroid use.

\section{A Giant papillae}

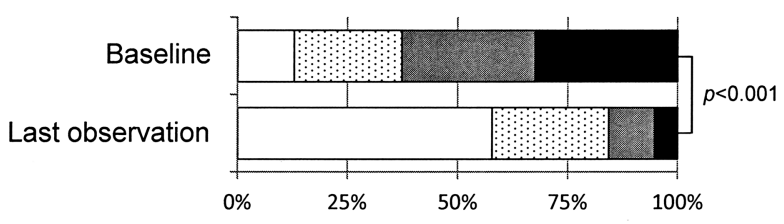

B Corneal involvement

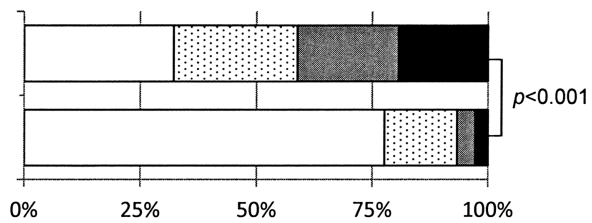

\begin{tabular}{|llll|}
\hline Score $\square: 0 \quad \square: 1 \quad \square: 2$ & $\square: 3$ \\
\hline
\end{tabular}

Figure 2 Distribution of giant papillae (A) and corneal involvement (B) scores. The statistical significance of each score change from baseline was evaluated using the Wilcoxon signed rank test. 


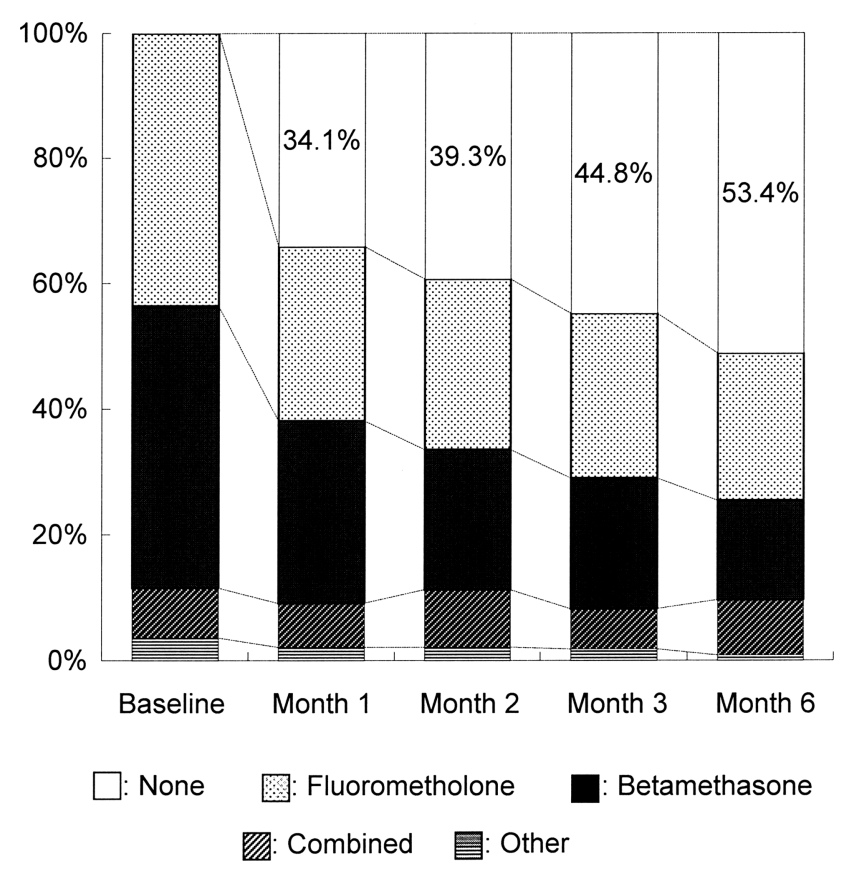

Figure 4 Proportions of patients using topical steroids at baseline and throughout the 6-month period during which the patients received topical tacrolimus eye drops.

\section{DISCUSSION}

In the past, antiallergic drug and/or steroid therapy has been used to treat severe allergic conjunctivitis (VKC, AKC) with proliferative lesions. Unfortunately, antiallergic drug therapy is often insufficient without concomitant steroid use. However, topical steroids put patients at high risk of developing cataracts and/or glaucoma. For severe disease, VKC most frequently occurs in children and young adults, while AKC typically begins

Table 3 Adverse drug reactions

\begin{tabular}{lr}
\hline Adverse drug reactions & Number of events (\%) \\
\hline Transient burning sensation in eye & $46(3.20)$ \\
Eye irritation & $34(2.37)$ \\
Eye pain & $10(0.70)$ \\
Hordeolum & $8(0.56)$ \\
Conjunctival hyperaemia & $6(0.42)$ \\
Eye pruritus & $4(0.28)$ \\
Foreign body sensation in eye & $3(0.21)$ \\
Eye discharge & $3(0.21)$ \\
Lacrimation & $3(0.21)$ \\
Lid herpes & $3(0.21)$ \\
Chalazion & $3(0.21)$ \\
Intraocular pressure elevation & $3(0.21)$ \\
Photophobia & $3(0.21)$ \\
Corneal ulcer & $2(0.14)$ \\
Conjunctival oedema & $2(0.14)$ \\
Punctate keratitis & $2(0.14)$ \\
Bacterial keratitis & $2(0.14)$ \\
Corneal erosion & $2(0.14)$ \\
Transient blurred vision & $2(0.14)$ \\
Herpetic keratitis & $2(0.14)$ \\
Other events (one each of 26 cases) & $1(0.07)$ \\
Overall: number of patients (\%) & $117(8.15)$ \\
\hline
\end{tabular}

in the late teens or early twenties. Unfortunately, AKC can persist into the fourth or fifth decade of life. ${ }^{18}$ Therefore, it is desirable to avoid long-term steroid use, particularly during childhood, to reduce the lifelong risk of developing steroid-related complications.

Tacrolimus has long been used in organ transplant patients and has been shown to have potent immunosuppressive activity. Moreover, tacrolimus has also been reported to inhibit calcineurin 100 times more effectively than cyclosporine. ${ }^{7}$ To evaluate the risks and benefits of tacrolimus eye drop use in patients with severe allergic conjunctivitis, the present large-scale study was conducted in a routine clinical setting. Changes in 10 clinical signs and 6 clinical symptoms were evaluated before and after tacrolimus eye drop therapy in 1436 patients. Twice daily treatment with tacrolimus eye drops resulted in a significant reduction in the score 1 month after the start of treatment. It has previously been shown that cyclosporine ophthalmic solution has a similar efficacy in patients with VKC and AKC. ${ }^{17}$ In accordance with the previous report, ${ }^{17}$ the present study showed that tacrolimus eye drops were effective in treating severe allergic ocular diseases with giant papillae or corneal involvement. Many of our study patients had previously used cyclosporine with no improvement. In addition, twice daily tacrolimus eye drop treatment significantly reduced the ocular sign and symptom score 1 month into treatment, even in patients with severe allergic conjunctivitis who had a poor response to cyclosporine.

The onset of VKC usually occurs before puberty, is more common in young male patients, and tends to abate in the mid to late teens. ${ }^{16} 18$ In VKC, proliferative changes, such as giant papillae formation, are notable and giant papillae may also occur in patients with AKC. ${ }^{19}$ Because vision-threatening keratopathy develops in an adjacent location to the giant papillae, alleviation of giant papillae seems to be an effective strategy in treating patients with proliferative lesions. In the present study, twice daily treatment with tacrolimus eye drops resulted in a marked reduction in active-stage giant papillae (score $\geq 2$ ) and a marked reduction in SPK. The percentage of patients having SPK decreased from $67.8 \%$ at baseline to $22.4 \%$ at the last observation. Additionally, the percentage of patients with a severe keratopathy score $(\geq 2)$ decreased from $52.8 \%$ to $8.4 \%$.

In the present study, concomitant use of steroids was allowed and was not an exclusion criterion. Steroids were used at the discretion of the attending physician. Our data showed that $53.4 \%$ of patients using steroids were successfully weaned from topical steroid therapy. Thus, tacrolimus eye drops appear to have a steroid-sparing or replacing effect. Because those in infancy or early childhood are at high risk for steroid-induced elevation of intraocular pressure, tacrolimus eye drops may be a very effective, alternative treatment for $\mathrm{VKC}$ or $\mathrm{AKC}$ that does not impose the risk of developing glaucoma.

Corneal infection was seen in five patients (herpetic keratitis (two cases), bacterial keratitis (two cases), bacterial corneal ulcer (one case)) for a total incidence of $0.35 \%$. This suggests that close monitoring during topical tacrolimus therapy is necessary during prolonged use. However, a previous study examining cyclosporine $0.1 \%$ aqueous ophthalmic solution showed a similar incidence of corneal infection, in which $5(0.84 \%)$ of 594 patients developed infectious corneal complications (bacterial corneal ulcer (two cases), herpetic keratitis (three cases)). ${ }^{17}$ This suggests that tacrolimus eye drops are equivalent to cyclosporine for the indications studied here.

Tacrolimus treatment may cause adverse reactions, including renal failure, when used systemically. ${ }^{20}$ In our study, no serious systemic adverse events were observed. This is likely because the percentage of tacrolimus reaching the bloodstream with twice- 
daily topical use is very low. ${ }^{21} 22$ In conclusion, we evaluated the efficacy and safety of tacrolimus eye drops in patients with VKC or AKC in a clinical setting. Our results suggest that topical tacrolimus therapy is safe and effective in treating patients with severe allergic conjunctivitis.

\section{Author affiliations}

${ }^{1}$ Department of Ophthalmology, Kochi Medical School, Kochi, Japan

${ }^{2}$ Department of Ophthalmology, Ehime University School of Medicine, Ehime, Japan ${ }^{3}$ Department of Ophthalmology, Juntendo University School of Medicine, Tokyo, Japan

${ }^{4}$ Department of Ophthalmology, Fukuoka University School of Medicine, Fukuoka, Japan

${ }^{5}$ Okamoto Eye Clinic, Ehime, Japan

${ }^{6}$ Kumagai Eye Clinic, Yamaguchi, Japan

${ }^{7}$ Department of Ophthalmology, Division of Visual Sciences, Nihon University School of Medicine, Tokyo, Japan

${ }^{8}$ Department of Ophthalmology, Tokyo Women's Medical University School of Medicine, Tokyo, Japan

${ }^{9}$ Nakagawa Eye Clinic, Osaka, Japan

${ }^{10}$ Department of Ophthalmology and Visual Science, Hokkaido University Graduate School of Medicine, Hokkaido, Japan

${ }^{11}$ Department of Ophthalmology, Tsurumi University Dental Hospital, Kanagawa, Japan

${ }^{12}$ Department of Ophthalmology, Tottori University School of Medicine, Tottori, Japan

Contributors All of the authors: conception and design; data acquisition; contributed to statistical analysis and interpretation; revised the article critically for important intellectual content. AF: drafted the article.

Funding This study was sponsored by Senju Pharmaceutical Co., Osaka, Japan.

\section{Competing interests None.}

Ethics approval The protocol for this study was reviewed by the Ethics Committee of the Pharmaceuticals and Medical Devices Agency in Japan.

Provenance and peer review Not commissioned; externally peer reviewed.

Open Access This is an Open Access article distributed in accordance with the Creative Commons Attribution Non Commercial (CC BY-NC 3.0) license, which permits others to distribute, remix, adapt, build upon this work non-commercially, and license their derivative works on different terms, provided the original work is properly cited and the use is non-commercial. See: http://creativecommons.org/ licenses/by-nc/3.0/

\section{REFERENCES}

1 Leonardi A, Motterle L, Bortolotti M. Allergy and the eye. Clin Exp Immunol 2008; 1:17-21.

2 Tabbara KF. Ocular complications of vernal keratoconjuctivitis. Can J Ophthalmol 1999;34:88-92.
3 Takamura $\mathrm{E}$, Uchio $\mathrm{E}$, Ebihara $\mathrm{N}$, et al. Japanese guideline for allergic conjunctival diseases. Allergol Int 2011;60:191-203.

4 Ohashi Y, Ebihara N, Fujishima $\mathrm{H}$, et al. A randomized, placebo-controlled clinica trial of tacrolimus ophthalmic suspension $0.1 \%$ in severe allergic conjunctivitis. J Ocul Pharmacol Ther 2010;26:165-73.

5 Ang M, Ti SE, Loh R, et al. Steroid-induced ocular hypertension in Asian children with severe vernal keratoconjunctivitis. Clin Ophthalmol 2012;6:1253-8.

6 Ohji M, Kinoshita S, Ohmi E, et al. Marked intraocular pressure response to instillation of corticosteroids in children. Am J Ophthalmol 1991;112:450-4.

7 Kino T, Hatanaka H, Hashimoto M, et al. FK-506, a novel immunosuppressant isolated from a Streptomyces. I. Fermentation, isolation, and physic-chemical and biological characteristics. J Antibiot (Tokyo) 1987:40:1249-55.

8 Sakuma S, Higashi Y, Sato N, et al. Tacrolimus suppressed the production of cytokines involved in atopic dermatitis by direct stimulation of human PBMC system. (Comparison with steroids.) Int Immunopharmacol 2001;1:1219-26.

9 Zhai J, Gu J, Yuan J, et al. Tacrolimus on the treatment of ocular diseases. Biodrugs 2011;25:89-103

10 Uno T, Yamaguchi T, Li XK, et al. The pharmacokinetics of water-in-oil-in-watertype multiple emulsion of a new tacrolimus formulation. Lipids 1997;32:543-8.

11 Pleyer U, Lutz S, Juske WJ, et al. Ocular absorption of topically applied FK506 from liposomal and oil formulations in the rabbit eye. Invest Ophthalmol Vis Sci 1993;34:2737-42.

12 Yura $\mathrm{H}$, Yoshimura $\mathrm{N}$, Hamashima $\mathrm{T}$, et al. Synthesis and pharmacokinetics of a novel macromolecular prodrug of tacrolimus (FK506), FK506-dextran conjugate. J Control Release 1999:57:87-99.

13 Miyazaki D, Tominaga T, Kakimaru-Hasegawa A, et al. Therapeutic effects of tacrolimus ointment for refractory ocular surface inflammatory diseases. Am J Ophthalmol 2008;115:988-92.

14 Lambiase A, Minchiotti S, Leonardi A, et al. Prospective, multicenter demographic and epidemiological study on vernal keratoconjunctivitis : a glimpse of ocular surface in Italian population. Ophthalmic Epidemiol 2009;16:38-41.

15 Calonge M. Classification of ocular atopic/allergic disorders and condition: an unsolved problem. Acta Ophthalmol Scand Suppl 1999;228:10-3.

16 Uchio E, Kimura R, Migita H, et al. Demographic aspects of allergic ocular diseases and evaluation of new criteria for clinical assessment of ocular allergy. Graefes Arch Clin Exp Ophthalmol 2008:246:291-6.

17 Ebihara N, Ohashi Y, Uchio E, et al. A large prospective observational study of novel cyclosporine $0.1 \%$ aqueous ophthalmic solution in the treatment of severe allergic conjunctivitis. J Ocul Pharmacol Ther 2009;25:365-71.

18 Bielory L. Allergic and immunologic disorders of the eye. Part II: ocular allergy. J Allergy Clin Immunol 2000;106:1019-32.

19 Guglielmetti S, Dart JK, Calder V. Atopic keratoconjunctivitis and atopic dermatitis. Curr Opin Allergy Clin Immunol 2010;10:478-85.

20 Przepiorka D, Nash RA, Wingard JR, et al. Relationship of tacrolimus whole blood levels to efficacy and safety outcomes after unrelated donor marrow transplantation. Biol Blood Marrow Transplant 1999;5:94-7.

21 Ebihara N, Ohashi Y, Fujishima $\mathrm{H}$, et al. Blood level of tacrolimus in patients with severe allergic conjunctivitis treated by $0.1 \%$ tacrolimus ophthalmic suspension. Allergol Int 2012;61:275-82.

22 Fujita E, Teramura Y, Shiraga T, et al. Pharmacokinetics and tissue distribution of tacrolimus (FK506) after a single or repeated ocular instillation in rabbits. J Ocul Pharmacol Ther 2008;24:309-19. 